\title{
Chemical Functionalization of Ceramic Tile Surfaces by Silane Coupling Agents: Polymer Modified Mortar Adhesion Mechanism Implications
}

\author{
Alexandra Ancelmo Piscitelli Mansur $r^{\mathrm{a}}$, Otávio Luiz do Nascimento, \\ Wander Luiz Vasconcelos ${ }^{\text {a }}$ Herman Sander Mansur ${ }^{\text {a* }}$ \\ ${ }^{a}$ Department of Metallurgical and Materials Engineering of Federal University of Minas Gerais, \\ Rua Espírito Santo, 35/316, Centro, 30160-030 Belo Horizonte - MG, Brazil \\ ${ }^{\mathrm{b}}$ Faculty of Engineering and Architecture of FUMEC University, \\ Rua Cobre, 200, Cruzeiro, 30310-190 Belo Horizonte - MG, Brazil
}

Received: April 3, 2008; Revised: August 6, 2008

\begin{abstract}
Adhesion between tiles and mortars are crucial to the stability of ceramic tile systems. From the chemical point of view, weak forces such as van der Waals forces and hydrophilic interactions are expected to be developed preferably at the tiles and polymer modified Portland cement mortar interface. The main goal of this paper was to use organosilanes as primers to modify ceramic tile hydrophilic properties to improve adhesion between ceramic tiles and polymer modified mortars. Glass tile surfaces were treated with several silane derivatives bearing specific functionalities. Contact angle measurements and Fourier Transform Infrared Spectroscopy (FTIR) were used for evaluating the chemical changes on the tile surface. In addition, pull-off tests were conducted to assess the effect on adhesion properties between tile and poly(ethylene-co-vinyl acetate), EVA, modified mortar. The bond strength results have clearly shown the improvement of adherence at the tile-polymer modified mortar interface, reflecting the overall balance of silane, cement and polymer interactions.
\end{abstract}

Keywords: polymer modified mortar, cladding, ceramic modifiers, bond strength

\section{Introduction}

In the construction industry, nanotechnology could potentially improve many building systems and explain some materials properties. Cement based materials are built up from the complex and complicated nanoscale structure of cement and its hydrates and, in several systems these "nano-effects" determine all the "macroscale" properties that are usually measured ${ }^{1}$. On the basis of recent molecular simulation and experimental studies, possible strategies for tuning the mechanical properties of cementitious materials by modifying the bonding scheme in the hydrates at molecular level are being discussed ${ }^{2}$. On ceramic tile systems it is not different. The overall result of adherence between ceramic tiles and polymer modified mortars could be explained considering the nano-order structure that is developed at the interface tile/mortar ${ }^{3}$.

Latex modified Portland cement mortars based on poly(ethyleneco-vinyl acetate), EVA, is the standard product in the market for ceramic tile installation ${ }^{4}$. However, based on chemical features of EVA and ceramic tiles, predominantly the weak van der Waals forces are expected to be developed at the tile-polymer modified mortar interface. On the other hand, surface modification is generally performed to modify its properties such as enhancing the interface adhesion between inorganic and organic materials. In this sense, silane coupling agents have been used for generating a hybrid (organic-inorganic) layer onto substrates ${ }^{5}$.

Until now, just few studies have been published in the literature that used silanes in systems based on Portland cement without polymer modification ${ }^{6-11}$. These studies reported surfaces of fibers, silica fumed, and cenospheres being modified with silanes or organosilanes which were added in mortars and concretes during mixing. In all cases, it was observed an increase on mechanical properties, but the mechanism of interaction was not deeply investigated. More recently, it was identified the possibility of developing strong bonds between some organosilanes and cement through covalent bonds ${ }^{12-14}$. Moreover, when considering EVA interaction with organosilanes, limited content of researches have been published and minor improvement on adherence was actually achieved ${ }^{15,16}$.

The possibility of bonding improvement at the interface between ceramic tiles and polymer modified mortars (PMM) is decisive for assuring stability to the adhered method as a reliable choice in ceramic tile installation. For this reason, in the last years, around the world, the lack of confidence has raised the concern from ceramic tiles and mortar industries with an overall result of reduction on the industrial growth and, indirectly, it has an adverse impact upon all manufactures, merchants and installers ${ }^{17-19}$. Besides that, when evaluating ceramic tile systems failures, adhesive rupture between cladding and modified mortar was observed in $84 \%$ of the buildings ${ }^{20}$. This value is not totally surprising when considering that the modeling of ceramic tile coverings behavior reveals the highest shear stresses in tile/tile bed interface, mostly related to stresses caused by moisture expansion or thermal movements ${ }^{21}$.

Hence, the main goal of this work was to promote a novel chemical functionalization of ceramic tiles surfaces by modifying with trialkoxysilanes coupling agents to generate an organic layer onto inorganic tile in order to enhance the interface adhesion between tile and polymer modified mortar. 


\section{Experimental Procedure}

\subsection{Tiles surface modification}

Soda-lime glass tiles $\left(\mathrm{SiO}_{2} \approx 70\right.$ wt. $(\%) ; \mathrm{Na}_{2} \mathrm{O} \approx 15$ wt. $(\%)$; $\mathrm{CaO} \approx 10$ wt. $(\%)$ ) with dimensions of $50 \times 50 \mathrm{~mm}$ were selected to be used as template for modeling the effect of silane modification in the adherence between EVA modified mortar and silane modified tile. This choice was based on the chemical similarity of glass tile compared to ceramic tile associated with the vitreous phase and composition for mimetizing inorganic substrate properties.

Glass tile surfaces were prepared with five silane derivatives bearing specific functionalities. Amino $\left(-\mathrm{NH}_{2}\right)$, mercapto $(-\mathrm{SH})$, vinyl $\left(-\mathrm{CH}=\mathrm{CH}_{2}\right)$, methacrylic $\left(\mathrm{CH}_{2}=\mathrm{C}\left(\mathrm{CH}_{3}\right) \mathrm{COO}-\right)$, and isocyanate $(-\mathrm{N}=\mathrm{C}=\mathrm{O})$ groups were chosen as reactive groups of coupling agents (Table 1) for evaluating their relative compatibility with the EVA mortar. The silanes were supplied by Sigma-Aldrich. Glass tile without any chemical modification (as supplied) was used as reference.

Prior to silane reaction, glass tile surface impurities were fully removed by immersion in $20 \%$ nitric acid for 2 hours, followed by deionized water (DI) rinse. After that, tiles were overnight dipped in DI water and air dried.

Hydroxylation $(-\mathrm{OH})$ was conducted by soaking tile samples in a 70:30 mixture of deionized water: $30 \%$ hydrogen peroxide $\left(\mathrm{H}_{2} \mathrm{O}_{2}\right)$ for 45 minutes at about $70{ }^{\circ} \mathrm{C}$. Then, $5 \mathrm{~mL}$ of $\mathrm{NH}_{4} \mathrm{OH}$ (conc.) were dropped for each $100 \mathrm{~mL}$ of the $\mathrm{H}_{2} \mathrm{O}: \mathrm{H}_{2} \mathrm{O}_{2}$ solution. After cooling, glass tile was rinsed in DI water and then dried in methanol. This increase of hydroxyl concentration is usually recommended and performed before silane application. This process enhances the density of available sites for silane reaction, improving surface modification process. Hydroxyl functionalization of glass results in the increase of silanol groups $(\mathrm{Si}-\mathrm{OH})$ at tile surface related to the reaction of silicon incomplete bonds minimizing free energy. The effect of this hydrophilic chemical functionalization with silanol groups in the adherence between EVA modified mortar and glass tile was also evaluated.

Silane modification procedure was conducted by dropping $500 \mu \mathrm{L}$ of alkoxysilane onto glass surface followed by spreading out using a sliding method with another glass tile. This silane layer was cured for 2 hours inside a water vapor chamber to ensure that hydrolysis and condensation reactions have occurred. After that, the tiles were rinsed with methanol to remove remaining unbounded silane from glass surface.

The process of surface tile modification is summarized in Figure 1.

\subsection{Hydrophobic/hydrophilic behavior via contact angle measurement}

The influence of surface functionalization on the hydrophilic/ hydrophobic behavior of glass tile was estimated via contact angle measurements that were carried out by depositing $50 \mu \mathrm{L}$ DI water $(18.0 \mathrm{M} \Omega)$ droplets on the glass tiles. The apparatus used for measurements was a digital camera Sony DSC-W30 with digital image analysis software.

\subsection{FTIR characterization}

FTIR was used to characterize the presence of organic chemical groups at the surface of inorganic glass tiles, reflecting the effectiveness of the developed procedure for chemical functionalization. Transmission technique was used (FTIR Spectrum 1000, Perkin Elmer) within the range between 4000 and $2700 \mathrm{~cm}^{-1}$. This range was chosen because it contains most important peaks of $-\mathrm{CH}$ stretching

Table 1. Organosilanes surface modifiers.

\begin{tabular}{|c|c|c|c|c|}
\hline \multirow[t]{2}{*}{ Reagent } & \multicolumn{3}{|c|}{ Chemical formula } & \multirow[t]{2}{*}{ Chemical structure } \\
\hline & Functional group & Spacer & Trialkoxy & \\
\hline 3-methacryloxy-propyl-trimethoxysilane & $\mathrm{CH}_{2}=\mathrm{C}\left(\mathrm{CH}_{3}\right) \mathrm{COO}-$ & $\left(\mathrm{CH}_{2}\right)_{3}$ & $\mathrm{Si}\left(\mathrm{OCH}_{3}\right)_{3}$ & \\
\hline Vinyl-trimethoxysilane & $-\mathrm{CH}=\mathrm{CH}_{2}$ & - & $\mathrm{Si}\left(\mathrm{OCH}_{3}\right)_{3}$ & \\
\hline 3-Isocyanate-propyl-triethoxysilane & $-\mathrm{N}=\mathrm{C}=\mathrm{O}$ & $\left(\mathrm{CH}_{2}\right)_{3}$ & $\mathrm{Si}\left(\mathrm{OCH}_{2} \mathrm{CH}_{3}\right)_{3}$ & \\
\hline 3-Mercapto-propyl-trimethoxysilane & $-\mathrm{SH}$ & $\left(\mathrm{CH}_{2}\right)_{3}$ & $\mathrm{Si}\left(\mathrm{OCH}_{2} \mathrm{CH}_{3}\right)_{3}$ & \\
\hline 3-Amino-propyl-triethoxysilane & $-\mathrm{NH}_{2}$ & $\left(\mathrm{CH}_{2}\right)_{3}$ & $\mathrm{Si}\left(\mathrm{OCH}_{2} \mathrm{CH}_{3}\right)_{3}$ & \\
\hline
\end{tabular}


without overlapping with glass characteristic peaks. Each spectrum was recorded with resolution of $2 \mathrm{~cm}^{-1}$ with a total of 32 scans.

\subsection{Mortar preparation, tile application, and pull-off test}

Portland cement type CPII-F 32 (Cimento Cauê) according to Brazilian Standard NBR 11578/91 was used to prepare the mortars. The composition and properties of the cement are summarized in Table 2. A commercial EVA redispersible powder (Wacker Chemie) was selected, with characteristics as presented in Table 3 .

Cement: sand ratio of 1:1.7 was used to prepare the mortar (in weight basis). The water/cement ratio was 0.60 and the polymer/cement ratio was $10 \%$. The mortar was manually mixed for 3 minutes and then it was let to rest for 10 minutes covered by a humid cloth, followed by 1 minute of mixing before use.

A single layer of cement mortar with average thickness of $6 \mathrm{~mm}$ was applied on the surface of a concrete substrate (Brazilian Standard NBR 14082/04, water absorption less than $0.5 \mathrm{~cm}^{3}$ and with more than 28 days of age). After five minutes of mortar application, unmodified and modified tiles were positioned over the mortar, followed by positioning a load of $10 \mathrm{~Pa}$ for 60 seconds on the top to promote even mortar spreading and penetration into surface roughness. Concrete substrates were placed in a chamber of controlled moisture and

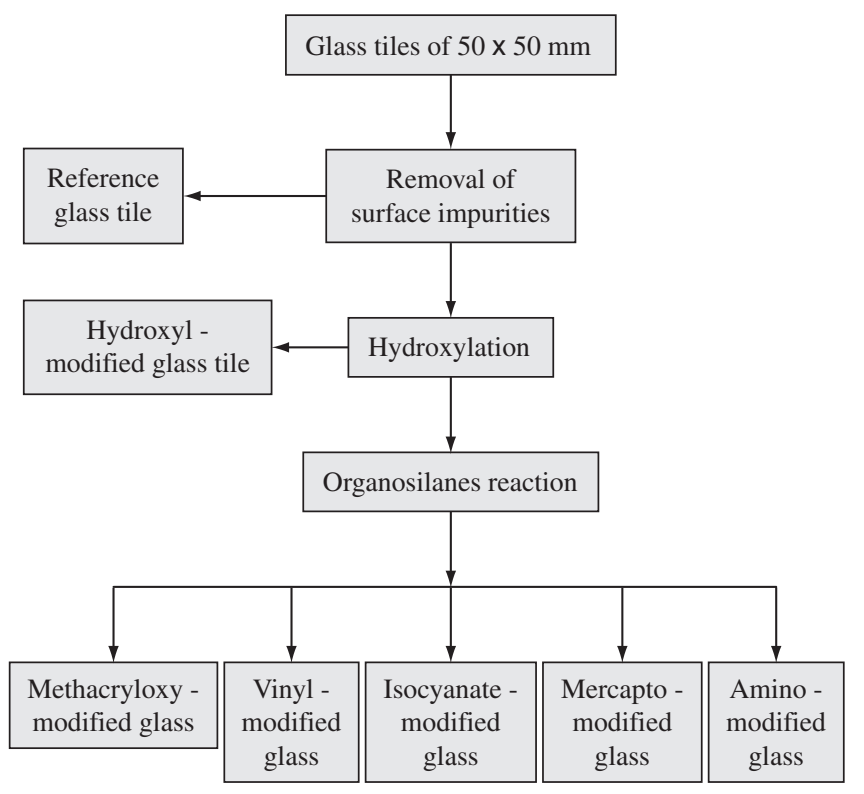

Figure 1. Flowchart of glass tile surface modification procedure. temperature $\left(\mathrm{T}=(25 \pm 5)^{\circ} \mathrm{C}\right.$ and $\left.\mathrm{RH}>90 \%\right)$ for 10 days followed by curing at laboratory environment conditions $\left(\mathrm{T}=(25 \pm 5)^{\circ} \mathrm{C}\right.$ and $\mathrm{RH}=(70 \pm 10) \%)$ for 14 days before pull-off tests.

Pull-off assays were performed following the procedures described in the Brazilian Standard NBR 14084/04 test method, allowing the determination of adhesion in tension (also named bond strength) of the tiles to the substrate. One day before the completion of the curing period, metallic pull head plates were glued onto the glass tiles using epoxy adhesive. After 24 hours of storage, each of these metallic plates was connected to the test machine for the direct pull-off tensile test (Figure 2). The bond strength of the specimens was calculated by dividing the maximum load (the load carried by the specimens at failure, F), by the area of the bonded surface (A), as shown in Equation 1. For each value, five measurements were always done.

$$
\text { Bond strength }(\mathrm{MPa})=\frac{\mathrm{F}(\mathrm{N})}{\mathrm{A}\left(\mathrm{mm}^{2}\right)}
$$

After the adhesion tests, the cross-sections of the specimens were observed for failure modes analysis, which were classified into the following three types: cohesive failure in polymer-modified mortar, adhesive failure at the interface tile/polymer-modified mortar, and

Table 2. Chemical properties of Portland cement CPII-F 32.

\begin{tabular}{|c|c|}
\hline Chemical composition & Weight $(\%)$ \\
\hline $\mathrm{SiO}_{2}$ & 18.6 \\
\hline $\mathrm{Al}_{2} \mathrm{O}_{3}$ & 4.4 \\
\hline $\mathrm{Fe}_{2} \mathrm{O}_{3}$ & 2.9 \\
\hline $\mathrm{CaO}$ & 62.6 \\
\hline $\mathrm{MgO}$ & 3.0 \\
\hline $\mathrm{SO}_{3}$ & 2.4 \\
\hline $\mathrm{Na}_{2} \mathrm{O}$ & 0.1 \\
\hline $\mathrm{K}_{2} \mathrm{O}$ & 0.9 \\
\hline $\mathrm{CO}_{2}$ & 4.3 \\
\hline Free $\mathrm{CaO}$ (lime) & 1.3 \\
\hline Loss on ignition & 4.8 \\
\hline Insoluble residue & 0.7 \\
\hline Major phases & Weight $(\%)$ \\
\hline $\mathrm{C}_{3} \mathrm{~S}-3 \mathrm{CaO} \cdot \mathrm{SiO}_{2}$ & 46.5 \\
\hline $\mathrm{C}_{2} \mathrm{~S}-2 \mathrm{CaO} \cdot \mathrm{SiO}_{2}$ & 20.0 \\
\hline $\mathrm{C}_{4} \mathrm{AF}-4 \mathrm{CaO} \cdot \mathrm{Al}_{2} \mathrm{O}_{3} \cdot \mathrm{Fe}_{2} \mathrm{O}_{3}$ & 9.7 \\
\hline $\mathrm{C}_{3} \mathrm{~A}-3 \mathrm{CaO} \cdot \mathrm{Al}_{2} \mathrm{O}_{3}$ & 6.0 \\
\hline $\mathrm{CaCO}_{3}$ & 9.8 \\
\hline
\end{tabular}

Table 3. Characteristics of EVA redispersible polymer powder.

\begin{tabular}{|c|c|c|}
\hline \multicolumn{2}{|c|}{ Properties } & Value \\
\hline \multicolumn{2}{|c|}{ Glass transition temperature $-\mathrm{Tg}\left({ }^{\circ} \mathrm{C}\right)$} & 16 \\
\hline \multicolumn{2}{|c|}{$\%$ Mass of Acetate } & $87 \%$ \\
\hline \multicolumn{2}{|c|}{$\%$ Mass of Ethylene } & $13 \%$ \\
\hline \multicolumn{2}{|c|}{ Minimum Film Formation Temperature (MFFT) of redispersion $\left({ }^{\circ} \mathrm{C}\right)$} & 4 \\
\hline \multicolumn{2}{|c|}{ Protective Colloid } & PVA \\
\hline \multirow[t]{2}{*}{ Particle Size } & Before redispersion & Maximum of $4 \%>400 \mu \mathrm{m}$ \\
\hline & After redispersion & $0.5-8 \mu \mathrm{m}$ \\
\hline \multicolumn{2}{|l|}{$\%$ Solids } & 99.4 \\
\hline \multicolumn{2}{|l|}{$\%$ Ash } & 10.1 \\
\hline \multicolumn{2}{|c|}{ Anti-caking agent } & kaolinite \\
\hline
\end{tabular}




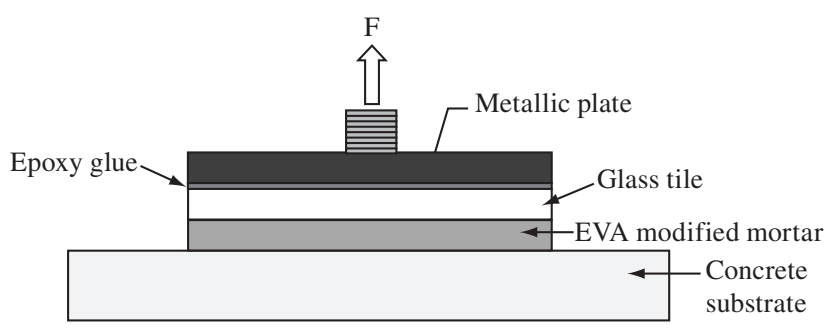

Figure 2. Test method for adhesion in tension for bond strength measurement.

cohesive failure in concrete substrate. Two or more modes can happen simultaneously resulting on a combined effect.

\section{Results and Discussion}

\subsection{Glass tile characterization}

Contact angle measurements indicated a significant difference on the hydrophilic behavior of the reference glass tile compared to those silane modified tiles. The dependence of contact angle with different chemical group can be observed in Figure 3. These values are in agreement with literature $e^{5,22,23}$ and with the critical superficial tension $(\gamma)$ of the modified surfaces ${ }^{24,25}$ (Figure 4 ).

The trend regarding to contact angle values was found to be crescent in the following order: Mercapto $<$ Methacryloxy $<$ Isocyanate $<$ Amino $<$ Vinyl, as expected in terms of the increase on the hydrophobic nature of this sequence of organosilanes. The opposite tendency (hydrophilic) was observed for hydroxyl ( $\mathrm{Si}-\mathrm{OH})$ modified surface when compared to the reference (unmodified) glass tile. It is noteworthy the relative high contact angle value reached with aminopropylsilane sample, despite of the presence of a high polar amine end group. This result is attributed to the configuration of this silane at the surface which is assumed to bend and orient its polar $\mathrm{NH}_{2}$ head toward the surface, driven by the formation of strong hydrogen bonds with the glass tile hydroxyl groups. Such configuration would leave ethylene sequences exposed at the surface, thus providing the hydrophobic character assessed through the contact angle ${ }^{23,26}$.

In Figure 5, FTIR spectra of glass tiles modified with trialkoxysilanes are shown. It can be verified the presence of the $-\mathrm{CH}$ stretching vibration bands (2850-3000 $\mathrm{cm}^{-1}$ ) introduced by the organic functionalization of the glass surface by all silanes precursors.

Therefore, the proposed procedures have proven to be effective on producing chemically modified surfaces with different functionalities on the inorganic substrate. Silanes have totally masked the glass tile hydroxyl groups and imposed their own surface properties. These findings are of paramount importance when considering that the adhesion phenomenon is mainly a consequence of forces acting at the tile-mortar interface. Therefore, as different chemical moieties are immobilized at the ceramic surface, the polymer organic chains from mortar will be impelled to a more stable tri-dimensional configuration. That overall behavior was evaluated by mechanical adhesion test.

\subsection{Bond strength test (pull-off results)}

Figure 6a shows the influence of the surface modification on the bond strength of mortars and Figure $6 \mathrm{~b}$ indicates the variation of bond strength due to surface modification.

Statistical analysis of bond strength results indicated a significant increase of adherence for glass tile modified with mercaptosilane $(95 \%$ of confidence). For this functional group $(-\mathrm{SH})$ we have also verified an important change of rupture mode from mostly interfacial failure

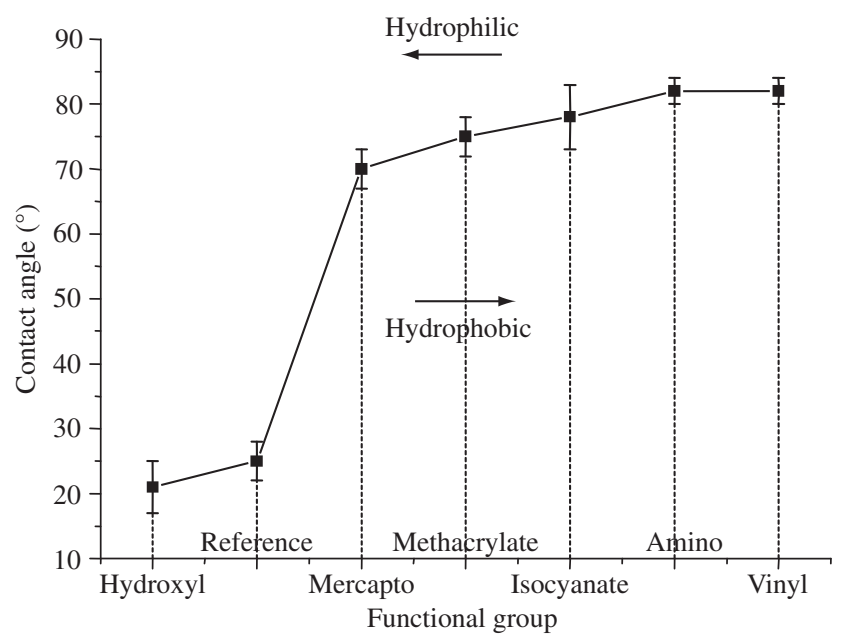

Figure 3. Contact angle measurements for control, hydrophilic and silane modified glass tiles.

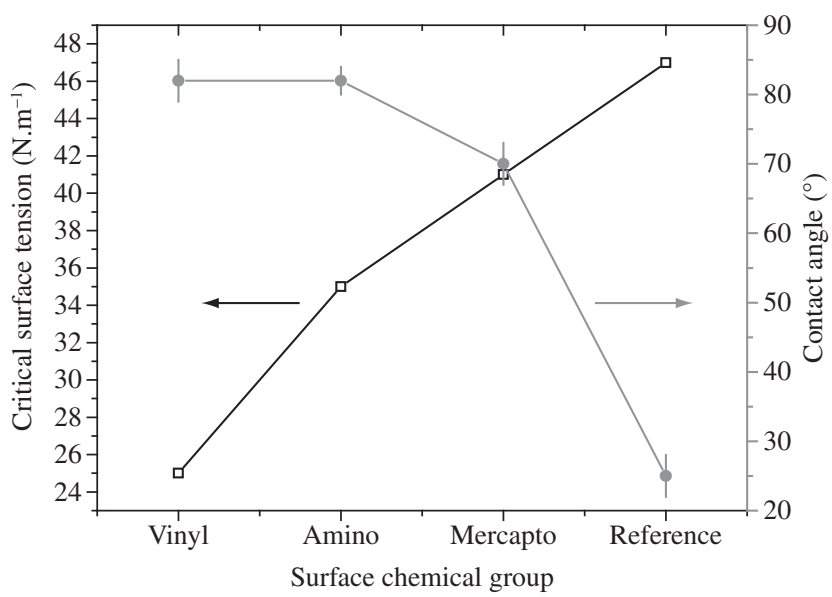

Figure 4. Contact angle measurements $x$ Critical surface tension (adapted from $\left.^{25}\right)$.

to a combined mode interfacial-cohesive of the mortar (Figure 7). As a matter of fact, for all tested surface chemical modifiers, except for vinylsilane, an increase of the bond strength was observed.

\subsection{Adhesion mechanisms}

When comparing reference glass tile and tile modified with silanol groups ( $\mathrm{Si}-\mathrm{OH})$, the improvement of bond strength of the mortar to the tile may be associated with the increase of density of hydrogen bonds between these groups introduced by chemical modification and the hydroxyl groups from EVA polymer (Figure 8). As previously reported for other polymeric systems ${ }^{3,27}$, an increase of adhesion between tiles and polymer modified mortar was explained by the formation of a hybrid interface ceramic-polymer-ceramic based on hydrogen bonds. As shown in Figure 9, polymers with hydroxyl side groups can act as chemical crosslinker agent between silanol from tile surface and water interlayer from nanostructured C-S-H of hydrated cement.

It is interesting to note that EVA latex does not contain readily available - $\mathrm{OH}$ groups but they are formed due the alkaline hydrolysis 


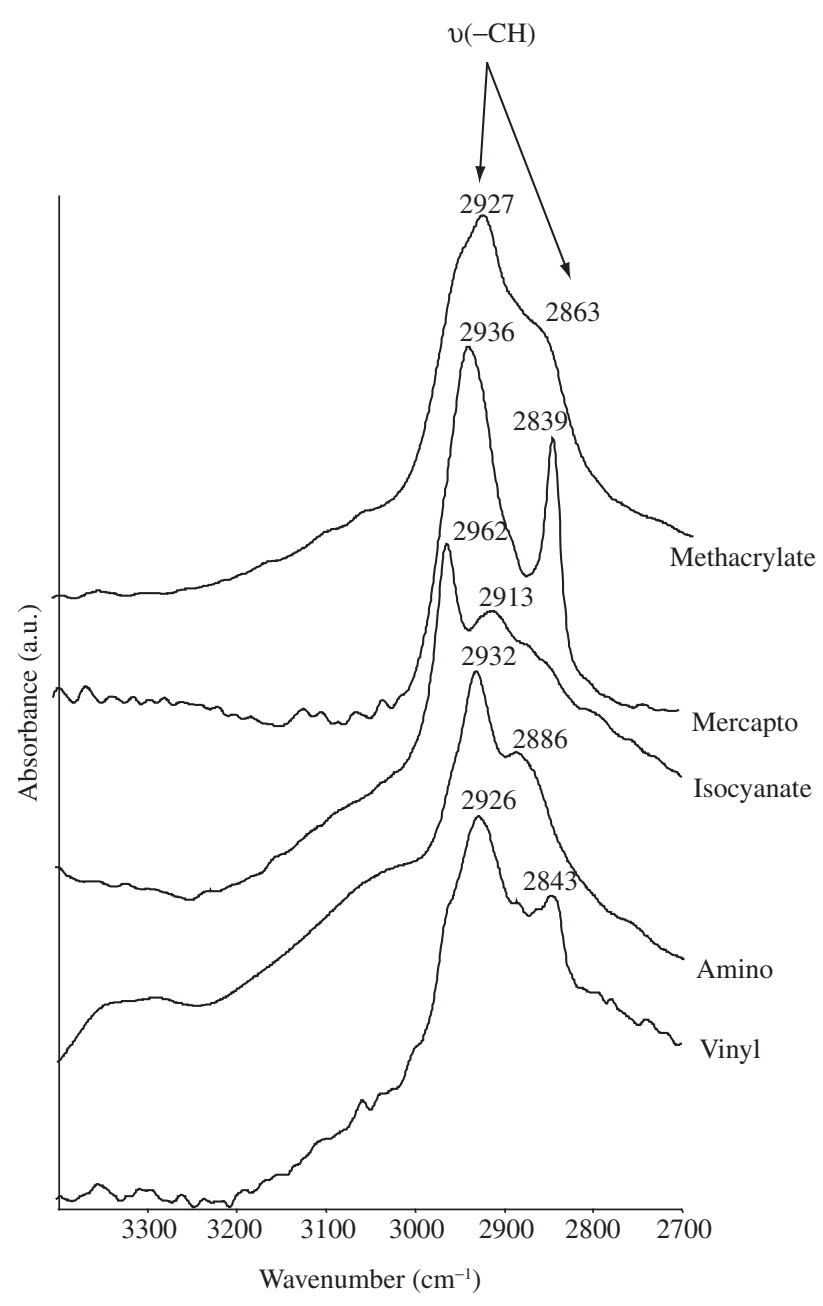

Figure 5. FTIR spectra for surface modified glass.

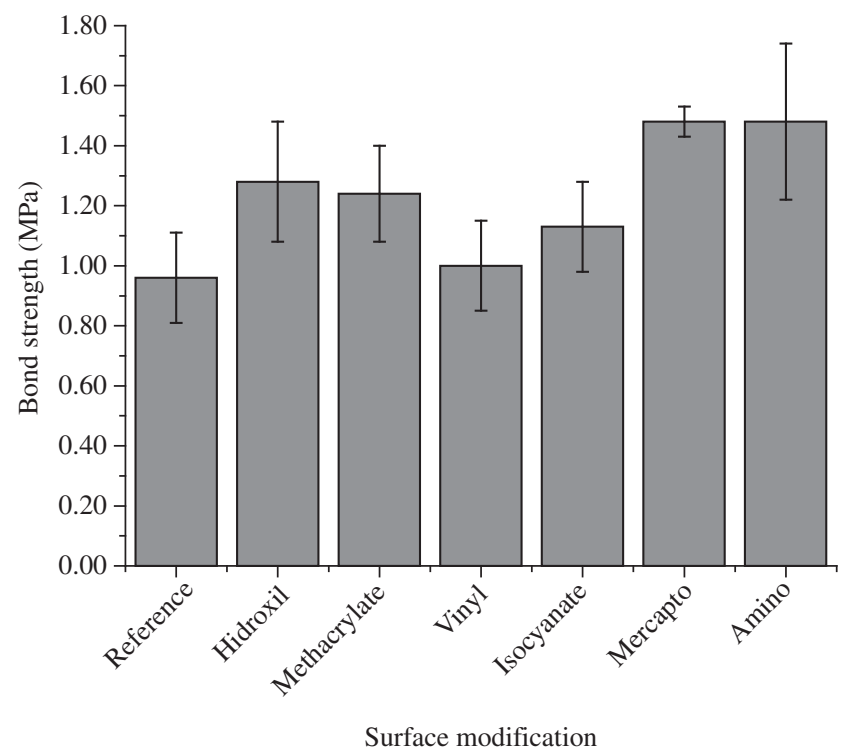

(a) of vinyl acetate sequences in the high $\mathrm{pH}$ medium characteristic of cement mortar ${ }^{28-30}$. Due to saponification (Figure 10), acetate radicals from PVAc (poly(vinyl acetate)) are partially or completely replaced by hydroxyl groups resulting in poly(vinyl alcohol) (PVA) sequences, with pendant $-\mathrm{OH}$ groups, with the polyethylene sequences remaining unaltered ${ }^{28}$. The rate of hydrolysis of VAc groups in the mortars can be indirectly evaluated through the FTIR spectra of Portland ce-

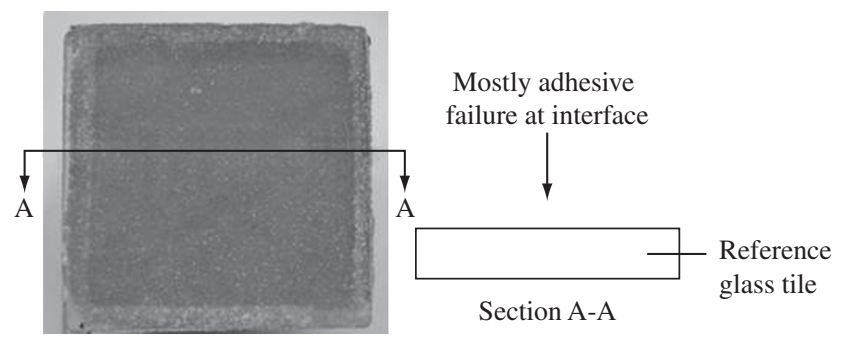

(a)

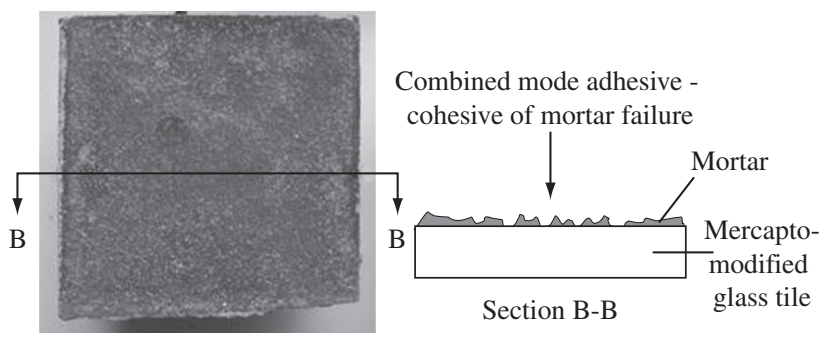

(b)

Figure 7. a) Interfacial mode of rupture for reference glass tile and; b) mixed mode interfacial-cohesive of the mortar due to mercaptosilane glass tile modification.

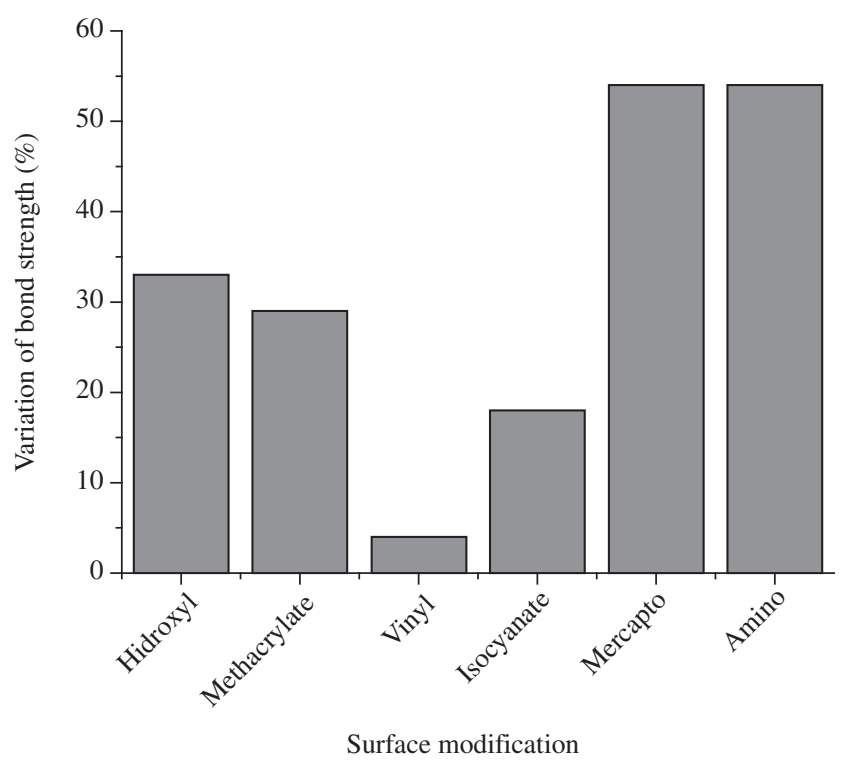

(b)

Figure 6. a) Effect of the surface modification on the bond strength of EVA modified Portland cement mortars to glass tiles; and b) Variation of bond strength due to surface modification. 
ment pastes modified with EVA at different ages ${ }^{29}$. In Figure 11, it is showed the spectra obtained from pure EVA polymer, reference paste without EVA e EVA modified pastes $(\mathrm{p} / \mathrm{c}=10 \%)$ with ages of 28 days and 150 days. FTIR spectrum of pure EVA (Figure 11b) revealed a strong band from carbonyl group $(\mathrm{C}=\mathrm{O})$ at $\mathrm{v}=1720-1740 \mathrm{~cm}^{-1}$ and a band associated with $\mathrm{C}-\mathrm{O}$ at $1242 \mathrm{~cm}^{-1[28,30]}$. Both are characteristic of PVAc sequences and do not overlap with cement paste peaks

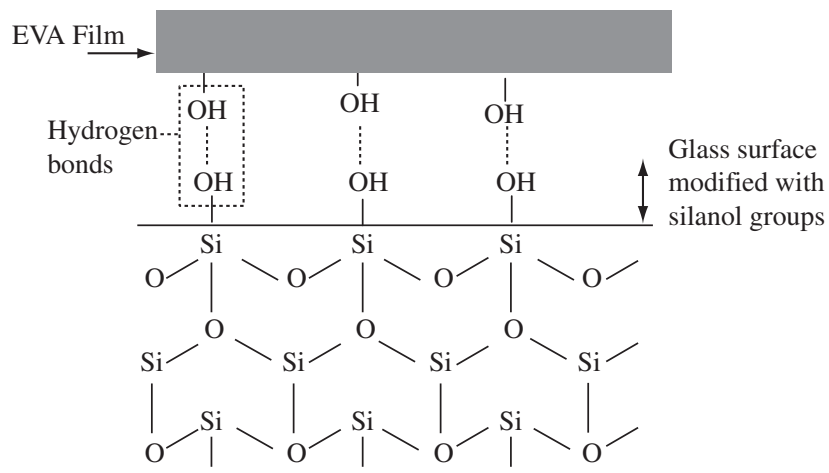

Figure 8. Hydrogen bonds between EVA and surface modified tile with silanol groups.

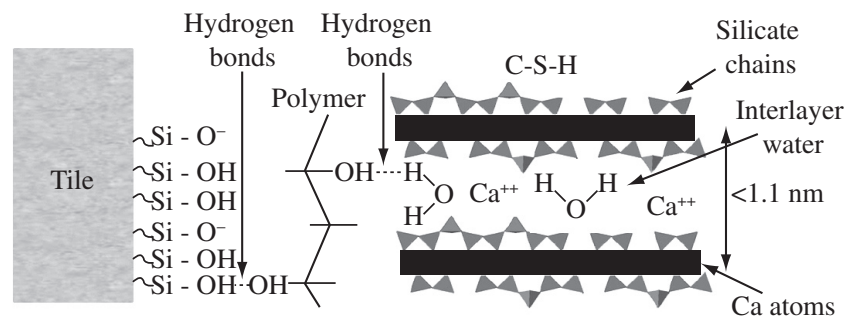

Figure 9. Schematic representation of nanostructured model for hybrid interface formation between porcelain tile and PVA modified mortar according to ${ }^{27}$ (not in scale).
(Figure 11a). These bands were relatively reduced (28 days) or even disappeared (150 days) in the cement paste modified with EVA. This was followed by the appearance of a peak at $1550 \mathrm{~cm}^{-1}$ related to the carboxylate group $\left(-\mathrm{COO}^{-}\right)$, a product of desacetylation reaction ${ }^{30}$. All these events are evidences of EVA hydrolysis with formation of $-\mathrm{OH}$ groups in the polymer chain.

When considering organosilane modified glass tiles, the higher bond strength observed compared to the reference sample can be attributed to the hydrophobic interaction of the propyl spacer from these silanes and the EVA ethylene sequences. The vinylsilane lacks of propyl spacer which is expected to reduce the degree of freedom on reaching a more stable tri-dimensional conformation at polymer interface. In addition, the unsaturated double bond with $\mathrm{sp}_{2}$ hybridization and planar structure significantly reduces hydrophobic interactions possibilities.

For mercaptosilanes and aminosilanes, in addition to the hydrophobic interactions, covalent bonds between alkoxy-derived and calcium silicate hydrates $(\mathrm{C}-\mathrm{S}-\mathrm{H})$ are likely to occur in some extent, increasing bond strength and leading to a cohesive rupture of mortar, as it could be observed in Figure 7. Minet et al. ${ }^{13}$ and Franceschini et al. ${ }^{14}$ have shown the incorporation of organic groups from alkoxysilanes in calcium silicate hydrates in alkaline media at room temperature without disrupting the C-S-H inorganic framework. These results were obtained for very small organic groups, like amines $\left(-\mathrm{NH}_{2}\right)$. For larger-sized or for highly hydrophobic organic groups, like vinyl, phase separation have occurred. Figure 12 summarizes the interactions between mercaptosilanes and EVA film.

\section{Conclusions}

The innovative method proposed for organosilane reaction at tile surface was efficient to make organically functionalized glass tiles as measured by contact angle and FTIR assays. All surface modifiers, except vinylsilane, have improved adherence between tile and polymer modified mortar, in some cases changing the mode of rupture from interfacial to a combined mode interfacial-cohesive at mortar. The enhancement on stability and interface adhesion was achieved by the development of hydrophilic, hydrophobic and even covalent bonds, besides the weak van der Waals forces, between EVA mortar and glass tile modified surface as a consequence of the effect

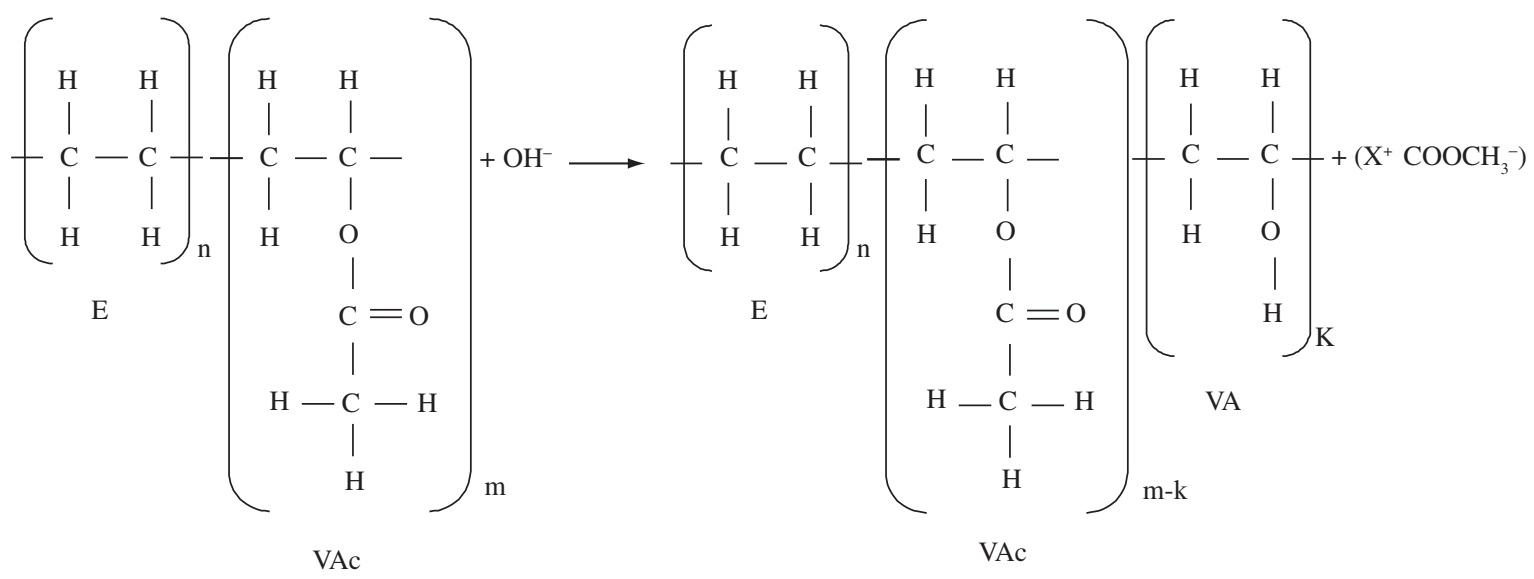

where: $\mathrm{n}=$ number of ethylene monomers
$\mathrm{m}=$ number of vinyl acetate monomers
$\mathrm{k}=$ number of vinyl alcohol monomers

Figure 10. Hydrolysis reaction from vinyl acetate units (VAc) to vinyl alcohol (VA) in EVA copolymer chain under alkaline medium. 


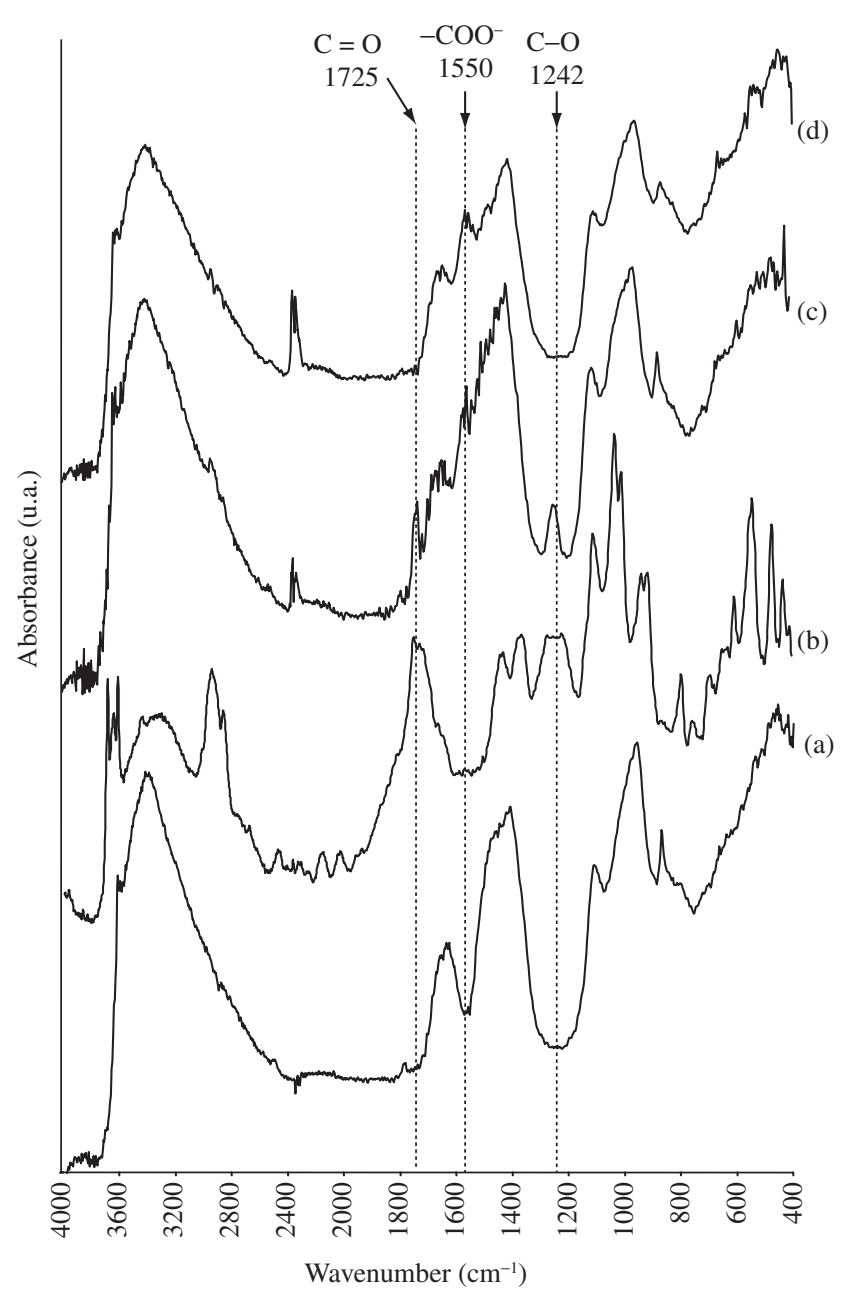

Figure 11. a) FTIR spectrum cement paste used as reference (without EVA), b) EVA copolymer, c) Cement paste modified with $10 \%$ of EVA aged for 28 days and d) 150 days.

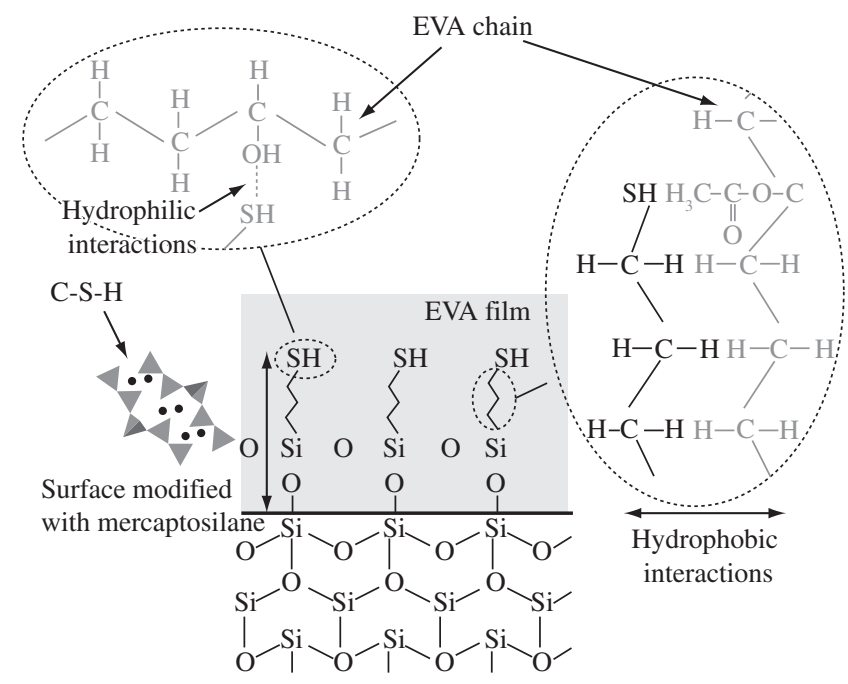

Figure 12. Schematic representation of physico-chemical interactions between mercaptosilanes and EVA films. of each silane on bond strength measured for the systems (cement, polymer, tile).

\section{Acknowledgements}

The authors acknowledge financial support from the CNPq, CAPES, and FAPEMIG.

\section{References}

1. Mann S. Nanotechnology and Construction. London: Institute of Nanotechnology; 2006. Available from: http://www.nanoforum.org.

2. Pellenq RJM, Lequeux N, Van Damme H. Engineering the bonding scheme in C-S-H: The iono-covalent framework. Cem. Conc. Res. 2008; 38(2):159-174.

3. Mansur AAP, Santos DB, Mansur HS. A microstructural approach to adherence mechanism of poly(vinyl alcohol) modified cement systems to ceramic tiles. Cem. Conc. Res. 2007; 37(2):270-282.

4. Schulze J, Killermann O. Long-term performance of redispersible powders in mortars. Cem. Conc. Res. 2001; 31(3):357-362.

5. Chu-jiang C, Zhi-gang S, Yu-shan X, Shu-lin, M. Surface topography and character of $\gamma$-aminopropyltriethoxysilane and dodecyltrimethoxysilane films adsorbed on the silicon dioxide substrate via vapor phase deposition. J. Phys. D: Appl. Phys. 2006; 39(22):4829-4837.

6. Fu X, Lu W, Chung DDL. Improving the tensile properties of carbon fiber reinforced cement by ozone treatment of the fiber. Cem. Conc. Res. 1996; 26(10):1485-1488

7. Xu Y, Chung DDL. Improving the workability and strength of silica fume concrete by using silane-treated silica fume. Cem. Conc. Res. 1999; 29(3):451-453.

8. Xu Y, Chung DDL. Carbon fiber reinforced cement improved by using silane-treated carbon fibers. Cem. Conc. Res. 1999; 29(5):773-776.

9. Xu Y, Chung DDL. Reducing the drying shrinkage of cement paste by admixture surface treatments. Cem. Conc. Res. 2000; 30(2):241-245.

10. McBride SP, Shukla A, Bose A. Processing and characterization of a lightweight concrete using cenospheres. J. Mat. Sci. 2002; 37(19):4217-4225.

11. Pehanich JL, Blankenhorn PR, Silsbee MR. Wood fiber surface treatment level effects on selected mechanical properties of wood fiber-cement composites. Cem. Conc. Res. 2004; 34(1):59-65.

12. Minet J, Abramson S, Bresson B, Sanchez C, Montlouillout V, Lequeux N. New Layered Calcium Organosilicate Hybrids with Covalently Linked Organic Functionalities. Chem. Mater. 2004; 16(21):3955-3962.

13. Minet J, Abramson S, Bresson B, Franceschini A, Van Damme H, Lequeux N. Organic calcium silicate hydrate hybrids: a new approach to cement based nanocomposites. J. Mater. Chem. 2006; 16(14):1379-1383.

14. Franceschini A, Abramson S, Mancini V, Bresson B, Chassenieux C, Lequeux N. New covalent bonded polymer-calcium silicate hydrate composite. J. Mater. Chem. 2007; 17(9):913-922.

15. Taylor HH, Wilmington D. Water-based adhesive from vinyl acetateethylene copolymer emulsion containing mercapto alkyl. US 3736283. 28 Dec 1970, 29 May 1973.

16. Bacher A, Stark K, Kornek T. Polyvinyl alcohols and polyvinyl acetals containing silane. US 20060052530. 17 Jul 2003, 09 Mar 2006.

17. Wan WC. Tiling failures - A chronic problem re-visited. Proceedings of the VIII World Congress on Ceramic Tile Quality; 2004 Fev 8-11; Castellon, Spain. Castellón: Logui Impresión; 2004; p. PGII49PGII56.

18. Diaz C. Ceramic tile pathologies. Proceedings of the VIII World Congress on Ceramic Tile Quality; 2004 Fev 8-11; Castellon, Spain. Castellón: Logui Impresión; 2004. p. PD3-PD9.

19. Cass C. Achieving $100 \%$ adhesive coverage. Proceedings of the VIII World Congress on Ceramic Tile Quality; 2004 Fev 8-11; Castellon, Spain. Castellón: Logui Impresión; 2004. p. PGII99-PGII107. 
20. Mansur AAP, Nascimento OL, Mansur HS. Data collection of five years of exterior facade pathologies in Brazil. Proceedings of the IX World Congress on Ceramic Tile Quality; 2006 Fev 12-15; Castellon, Spain. Castellón: Logui Impresión; 2006. p. PBB107-PBBI20.

21. Abreu M, Leitão V, Lucas J C. Modeling the behavior of ceramic tile covering. Proceedings of the VIII World Congress on Ceramic Tile Quality; 2004 Fev 8-11; Castellon, Spain. Castellón: Logui Impresión; 2004. p. PGII3-PGII17.

22. Mansur HS, Lobato ZIP, Oréfice RL, Vasconcelos WL, Oliveira C, Machado L. Surface Functionalization of Porous Glass Networks: Effects on Bovine Serum Albumin and Porcine Insulin Immobilization. Biomacromol. 2000; 1(4):789-797.

23. Abdelmouleh M, Boufi S, Belgacem MN, Duarte AP, Ben Salah A, Gandini A. Modification of cellulosic fibres with functionalised silanes: development of surface properties. Int. J. Adhes. Adhesives. 2004; 24(1):43-54.

24. Matilinna JP, Vallitu PK. Silane Based Concepts on Bonding Resin Composite to Metals. J. Contemp. Dent. Pract. 2007; 8(2):1-13
25. Gelest Inc. Silane Coupling Agents: Connecting Across Boundaries. Morrisville: Gelest Inc.; 2006. 58p (Technical Bulletin). Available from: http://www.gelest.com.

26. Chiang $\mathrm{CH}$, Ishida H, Kooing JL. The structure of $\gamma$-aminopropyltriethoxysilane on glass surfaces. J Colloid Interface Sci. 1980; 74(2):396-404.

27. Mansur AAP, Mansur, HS. Interface Porcelain Tile/PVA Modified Mortar: A Novel Nanostructure Approach. J. Nanosci. Nanotechnol. 2008. (In press).

28. Fonseca C, Fatou JG, Perena JM. Study of the acetoxy-hydroxide transformation in ethylene-vinyl acetate copolymers. Die Angew. Makromol. Chem. 1991; 190(1):137-155.

29. Mansur AAP. Mecanismos de aderência na interface argamassa e revestimento cerâmico de fachadas. [PHD thesis]. Belo Horizonte: Escola de Engenharia da Universidade Federal de Minas Gerais - EEUFMG; 2007. 326 p.

30. Silva DA, Roman HR, Gleize PJP. Evidences of chemical interaction between EVA and hydrating Portland cement. Cem. Conc. Res. 2002; 32(9):1383-1390. 